\title{
Intraspecific tetraploid hybrids of Paspalum notatum: agronomic evaluation of segregating progeny
}

\author{
Roberto Luis Weiler ${ }^{1}$, Miguel Dall'Agnol ${ }^{1}$, Carine Simioni ${ }^{*}$, Karine Cristina Krycki ${ }^{1}$, Emerson André Pereira ${ }^{2}$, Juliana Medianeira \\ Machado $^{3}$, Éder Alexandre Minski da Motta ${ }^{1}$
}

${ }^{1}$ Federal University of Rio Grande do Sul - Dept. of Forage Plant and Agrometeorology, Av. Bento Gonçalves, 7200 91450-000 - Porto Alegre, RS - Brazil.

2Regional University of Northwestern Rio Grande do Sul Dept. of Agrarian Studies, R. do Comércio, 3000 - 98700000 - ljuí, RS - Brazil.

3University of Cruz Alta/Center for Health and Agrarian Sciences, Rod. Jacob Della Méa, km 5,6 - 98005-972 Cruz Alta, RS - Brazil.

*Corresponding author < carine.simioni@ufrgs.br>

Edited by: James Pierre Muir

Received September 15, 2016

Accepted January 05, 2017
ABSTRACT: For many decades, animal production in southern Brazil has been based on native forage grasses. Paspalum notatum Flügge (bahiagrass) is one of the most frequently used native grass in southern Brazil. The native germplasm of $P$. notatum is tetraploid and displays apomictic reproduction; hence, chromosome doubling of sexual diploid accessions is required to facilitate hybridization. The main goal of this study was to evaluate forage production and other agronomical evaluation of $P$. notatum intraspecific hybrids in order to obtain new varieties that could be registered and/or protected and launched as new cultivars in the future. Three tetraploid sexual genotypes were crossed with the ecotypes Bagual and André da Rocha. Biomass production (leaf, stem, and inflorescence fractions), plant growth habit, plant height, number of tillers, and frost damage were evaluated in the resulting hybrids. The general combining ability (GCA) and specific combining ability (SCA) were calculated for the six families generated. We evaluated 196 hybrids and the most productive yielded $42 \%$ more total dry mass than the most productive parent (ecotype Bagual), and Bagual production was seven-fold higher than that of cultivar 'Pensacola'. The highest GCA values were observed for Bagual and Q4205. No correlation was observed between leaf coloration and the frost effect or regrowth in the following winter. Similarly, no correlation between plant growth habit and dry mass production was observed. The reproduction mode of the most productive hybrids are currently being analyzed in larger plots to identify apomictic and sexual genotypes for future registration and protection.

Keywords: bahiagrass, hybridization, forage yield

\section{Introduction}

Native grasses from southern Brazil have comprised the basic resource for livestock production for many decades. Inadequate management and biotic limitations have led to the current state of pasture degradation. Native pastures of the state of Rio Grande do Sul play an important role in animal production, accounting for the largest resource for beef cattle production. The most prominent native grasses belong to the genus Paspalum L., which have good forage value and grow well in hot climates (Nabinger et al., 2009). However, in cold temperatures, the plants present reddening of leaves and rhizomes due to flavonoid accumulation, which can be used as a morphological marker to assess cold stress tolerance (Moon et al., 2006). P. notatum Flügge (bahiagrass) is one of the most prevalent native species in southern Brazil, with good forage quality and high resistance to grazing and animal trampling (Cidade et al., 2013).

Cytological studies have found that most Paspalum species are predominantly tetraploid that reproduce by apomixis and have a counterpart diploid cytotype that reproduces sexually (Ortiz et al., 2013). The native $P$. notatum germplasm from Rio Grande do Sul is tetraploid and displays apomictic reproduction (Forbes and Burton, 1961). Completely sexual tetraploid plants were produced directly from sexual diploids plants of natural bahiagrass populations by colchicine treatment (Quarin et al., 2001, 2003; Weiler et al., 2015). The subsequent use of duplicate genotypes in intraspecific mating systems opens new possibilities for breeding programs (Rebozzio et al., 2012).

The apomictic F1 hybrids derived from sexual $x$ tetraploid crosses can enter agronomic performance in field trials. The forage seed market has great interest to register and protect varieties with higher forage yield than the "common" cultivars available. The plants used in this study, which display superior agronomic traits, are immediate candidates as new cultivars to promote pasture diversification with increased productivity (Simioni and Valle, 2011). This study evaluated forage production and other agronomical evaluation of $P$. notatum intraspecific hybrids. In addition, GCA and SCA were used to identify the best parents to be used in future crossings within the forage breeding program. The correlation between anthocyanin with cold tolerance as well as between plant growth habit and dry mass production was measured.

\section{Materials and Methods}

The study was performed in Eldorado do Sul in the state of Rio Grande do Sul (latitude $30^{\circ} 29^{\prime}$ S, longitude $51^{\circ} 06^{\prime} \mathrm{W}$ and altitude $62 \mathrm{~m}$ ). The local climate is Cfa: subtropical with no defined dry season and the temperature of the hottest month is above $22^{\circ} \mathrm{C}$. The average minimum and maximum annual temperatures 
in the region are $14{ }^{\circ} \mathrm{C}$ and $24.2{ }^{\circ} \mathrm{C}$, respectively, and the annual average temperature is $19.6^{\circ} \mathrm{C}$. The average annual rainfall is $1.398 \mathrm{~mm}$, and the average annual relative humidity is $79 \%$.

Three tetraploid sexual genotypes, Q4188, Q4205 (Quarín et al., 2003), and C44X (Quarín et al., 2001), were obtained in collaboration with the Botanical Institute of Northeast Argentina (IBONE), Corrientes, Argentina, and were crossed with elite tetraploid germplasm native to the state of Rio Grande do Sul ecotypes Bagual and André da Rocha. The crosses were performed using the methodology described by Burton (1948) in order to obtain a hybrid progeny. We obtained 250 hybrids from crosses between the female parents Q4188, Q4205, and C44X and the male parents André da Rocha and Bagual of which 196 were evaluated in the field (through four replicates). Moreover, four clones of the parents and the cultivar 'Pensacola' were evaluated with random distribution. Twenty-nine hybrids of progeny A (Q4188 $\times$ André da Rocha), 44 of progeny B (Q4188 $\times$ Bagual), 37 of progeny C (Q4205 $\times$ André da Rocha), 27 of progeny D (Q4205 × Bagual), 26 of progeny E (C44X $\times$ André da Rocha), and 33 of progeny $\mathrm{F}(\mathrm{C} 44 \mathrm{X} \times$ Bagual) were evaluated.

The F1 seeds were germinated in Petri dishes containing germitest paper and the resultant seedlings were transferred into honeycombed trays containing commercial substrate when they presented their first fully expanded leaves. When the plants presented four or more tillers, the tillers were separated into four different pots to obtain four clones to be used as replicates in the field. These replicates were planted in the field with $1 \mathrm{~m}$ spacing between plants within and between rows, using a completely randomized experimental design. Immediately after transplantation, the plants were watered using sprinkler irrigation to facilitate seedling establishment.

Two cuttings were taken during the $1^{\text {st }}$ year of evaluation to estimate dry mass production, and three cuttings were taken during the $2^{\text {nd }}$ year. The plants were cut when they reached an average height of 20 $\mathrm{cm}$, leaving a residue of $5 \mathrm{~cm}$ from the ground height. The collected plants were separated into three groups: leaves (leaf blades), stems (stems and sheaths), and inflorescences. Plant growth habit was visually evaluated at each cutting. Five classes of plant growth habit were assigned based on a scale of 1 to 5 , where 1 meant "prostrate", and 5 meant "erect". The number of tillers per plant was quantified by counting all tillers presenting expanded leaves and plant height was measured using a graduated ruler (Figures $1 \mathrm{~A}$ and $\mathrm{B}$ ).

Similarly, intensity of leaf coloration was assessed visually before the first frost in the field during winter to investigate possible correlations between anthocyanin accumulation with cold tolerance and with the regrowth following winter. Leaf color was scored on a scale of 0 to 10 in which 0 represented plants with completely green leaves and 10 referred to red leaves.
The effects of cold were evaluated in the spring through qualitative scoring of leaf damage on a scale of 1 to 4 , where 1 represented plants showing little or no damage and 4 meant plants with many or all leaves affected. Plant survival following the winter period was evaluated in the next spring, using a scale from 1 to 4 , where 1 represented plants with low survival and 4 referred to plants with a vigorous of regrowth.

The data were computed and analyzed using SAS (Statistical Analysis System, version 6.12). Total dry mass (TDM), leaf dry mass (LDM), inflorescence dry mass (IDM), stem dry mass (SDM), plant height, and number of tillers for each accession were compared with the control, ecotype Bagual, using Dunnett's test for multiple comparison ( $p \leq 0.05)$. The ecotype Bagual was used as a control because it is tetraploid and presented a good performance in previous trials outyielding cultivar 'Pensacola'

The General Combining Ability (GCA) and Specific Combining Ability (SCA) were calculated for all the hybrids of the six families generated. Finally, correlations between LDM, SDM, IDM, TDM, number of tillers, plant height and between TDM and number of tillers were performed. Additionally, TDM for the third cutting, plant growth habit, leaf anthocyanin coloration, frost effect, and survival following winter were analyzed using the Pearson product-moment correlation coefficient.

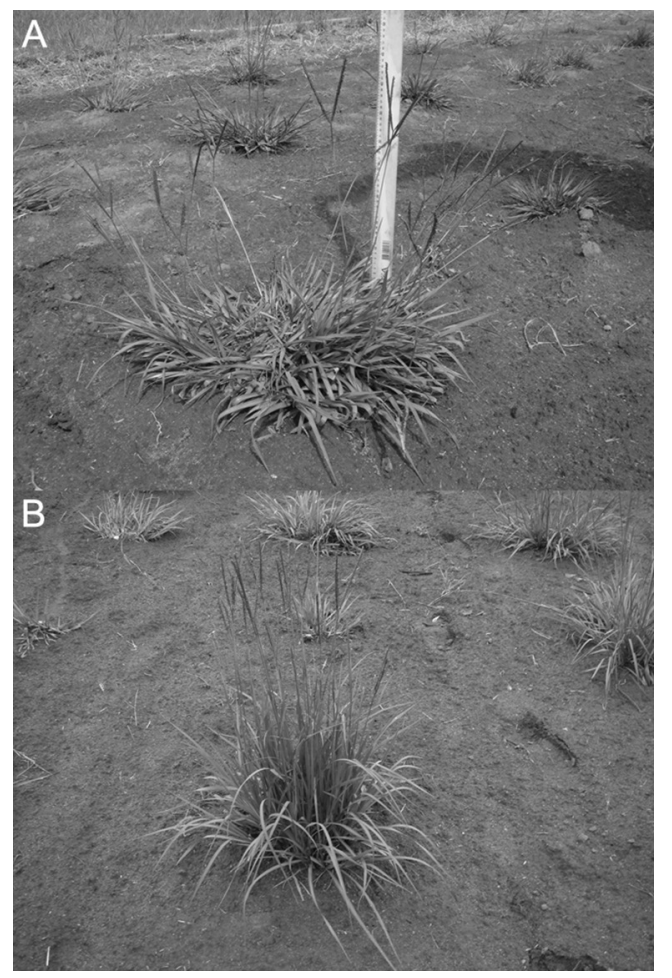

Figure 1 - Measurement of plant height using a graduated ruler and evaluation of the plant growth habit: (A) prostrate plant, and (B) erect plant. 


\section{Results and Discussion}

The average dry mass production for the 20 most productive genotypes among all the 196 hybrids, the parents, cultivar 'Pensacola', and the five least productive genotypes are presented in Table 1. The TDM for each cutting was compared to ecotype Bagual, which was the most productive male parent. The rankings of the most productive genotypes varied among the cuttings with the more pronounced changes occurring following the winter of 2011, due to the differential response of the genotypes to low temperatures (Table 1). Total dry matter production decreased in the spring cuttings of all hybrids, even those with good production in the $1^{\text {st }}$ year, but increased again in subsequent cuttings.

Hybrids D17 and C17 had good production in the first four cuttings, but did not follow the production increase of the remaining genotypes in the fifth cutting (Table 1). Hybrids C15, C1, C23, B8, B29, B28, D6, B4, D25, C35, D24, and A13 were among the 20 most pro- ductive during the $1^{\text {st }}$ year of production; however, they did not maintain the same performance levels following winter, and were not among the most productive genotypes in the $2^{\text {nd }}$ year of production. A similar behavior was observed for genotype $\mathrm{C} 15$, which was the fifth most productive in the $1^{\text {st }}$ year, but reduced its production in the $2^{\text {nd }}$ year.

Hybrid D3 had the highest cumulative dry mass production for the five cuttings (597 g TDM per plant) and its total yield was $42 \%$ higher than that of the most productive parent, ecotype Bagual (420 g TDM per plant). The seasonal distribution of TDM production of some selected genotypes, highlighting the male parents Bagual and André da Rocha, which presented the highest productivity, increased in the fourth cutting and some of the highest productivities in the fifth and final cuttings. This response could be attributed to the adaptation potential that native ecotypes have.

The five most productive hybrids had higher production than the remaining genotypes, including their

Table 1 - Total dry mass (TDM) production for the five cuttings, in grams, of the 20 most productive genotypes, the five least productive genotypes, parents, and cultivar 'Pensacola'.

\begin{tabular}{|c|c|c|c|c|c|c|c|c|c|c|}
\hline \multicolumn{4}{|c|}{ TDM Year 1} & \multicolumn{5}{|c|}{ TDM Year 2} & \multicolumn{2}{|c|}{ Cumulative TDM for the 2 years } \\
\hline Genotype & Cutting 1 & Cutting 2 & Total & Genotype & Cutting 3 & Cutting 4 & Cutting 5 & Total & Genotype & Total \\
\hline D3 & $96.7^{*}$ & $70.0^{*}$ & 166.7 & D3 & $112.3^{*}$ & 80.1 & 238.0 & 430.4 & D3 & $597^{*}$ \\
\hline D17 & $64.2^{*}$ & 65.2 & 129.3 & B43 & 59.7 & 50.2 & 247.8 & 357.7 & D16 & 456 \\
\hline $\mathrm{C} 17$ & $67.7^{*}$ & 59.1 & 126.7 & $\mathrm{C} 24$ & 89.0 & 69.1 & 196.7 & 354.8 & $\mathrm{C} 17$ & 454 \\
\hline D16 & $58.9^{*}$ & 59.0 & 117.8 & B17 & 77.5 & 56.6 & 215.2 & 349.2 & $\mathrm{C} 2$ & 446 \\
\hline $\mathrm{C} 15$ & $62.8^{*}$ & 51.6 & 114.4 & D16 & 81.6 & 57.9 & 198.9 & 338.4 & B17 & 439 \\
\hline C2 & $60.6^{*}$ & 52.5 & 113.1 & F15 & 35.4 & 57.0 & 241.7 & 334.1 & D17 & 438 \\
\hline $\mathrm{C} 1$ & $58.2^{*}$ & 50.6 & 108.7 & $\mathrm{C} 2$ & 78.4 & 83.6 & 170.9 & 332.9 & B43 & 425 \\
\hline $\mathrm{C} 23$ & 52.2 & 50.9 & 103.1 & $\mathrm{C} 18$ & $92.1^{*}$ & 49.6 & 189.8 & 331.5 & $\mathrm{C} 24$ & 425 \\
\hline B8 & 42.0 & 54.8 & 96.7 & C17 & $93.5^{*}$ & 60.4 & 173.5 & 327.4 & D25 & 414 \\
\hline B29 & 43.5 & 51.4 & 94.9 & C32 & 59.8 & 63.1 & 201.3 & 324.1 & $\mathrm{C} 18$ & 412 \\
\hline B28 & 43.9 & 49.7 & 93.6 & D25 & 49.9 & 58.9 & 214.1 & 322.8 & F15 & 405 \\
\hline D6 & 41.8 & 51.4 & 93.2 & C9 & 71.8 & 48.9 & 190.7 & 311.3 & F29 & 392 \\
\hline B4 & 43.2 & 49.5 & 92.6 & F24 & 33.2 & 62.9 & 213.8 & 310.0 & B26 & 388 \\
\hline D25 & 41.2 & 49.7 & 90.8 & D17 & 81.7 & 47.9 & 179.1 & 308.6 & B37 & 377 \\
\hline B17 & 41.8 & 48.1 & 89.9 & B37 & 81.8 & 58.8 & 165.6 & 306.2 & F24 & 372 \\
\hline C35 & 48.8 & 39.7 & 88.5 & B26 & 70.6 & 60.8 & 173.2 & 304.5 & C32 & 366 \\
\hline F29 & 47.5 & 40.5 & 88.0 & F29 & 30.6 & 51.8 & 221.4 & 303.7 & C9 & 363 \\
\hline D24 & 44.1 & 41.3 & 85.4 & C6 & 48.9 & 60.1 & 186.5 & 295.5 & C6 & 362 \\
\hline A13 & 43.6 & 39.6 & 83.2 & A20 & 55.8 & 49.4 & 182.2 & 287.3 & C15 & 360 \\
\hline B26 & 42.4 & 40.6 & 83.0 & D23 & 44.5 & 38.2 & 191.3 & 273.9 & B29 & 356 \\
\hline BAGUAL & 20.5 & 26.9 & 47.4 & BAGUAL & 40.9 & 74.0 & 258.6 & 373.4 & Bagual & 421 \\
\hline André da Rocha & 8.6 & 9.9 & 18.6 & André da Rocha & 19.0 & 48.8 & 224.2 & 292.0 & André da Rocha & 311 \\
\hline Q4188 & 19.3 & 29.9 & 49.2 & Q4188 & 38.6 & $25.8^{*}$ & $79.8^{*}$ & 144.3 & Q4188 & 193 \\
\hline Q4205 & 10.8 & 12.2 & 23.0 & Q4205 & 9.3 & $6.5^{*}$ & $22.2^{*}$ & 38.0 & Q4205 & 55 \\
\hline C44X & 1.8 & 1.6 & 3.4 & C44X & 4.5 & $8.3^{*}$ & $32.4^{*}$ & 45.1 & C44X & 50 \\
\hline 'Pensacola' & 4.6 & 6.3 & 10.9 & 'Pensacola' & 10.9 & $19.8^{*}$ & $45.4^{*}$ & 76.1 & ‘Pensacola' & 87 \\
\hline D21 & 2.5 & 2.0 & 4.5 & E5 & 2.8 & $3.3^{*}$ & $17.3^{*}$ & 23.5 & E5 & $34^{*}$ \\
\hline F5 & 1.7 & 1.4 & 3.0 & A35 & 6.3 & $3.5^{*}$ & $11.9^{*}$ & 21.7 & F5 & $28^{*}$ \\
\hline E22 & 0.9 & 0.9 & 1.8 & $\mathrm{D} 21$ & 4.2 & $2.1^{*}$ & $9.6^{*}$ & 15.9 & A35 & $23^{*}$ \\
\hline D15 & 0.8 & 1.2 & 1.6 & E19 & 2.7 & $3.3^{*}$ & $9.7^{*}$ & 15.6 & D21 & $22^{*}$ \\
\hline A21 & 0.2 & 0.2 & 0.4 & D15 & 1.6 & $0.9^{*}$ & $7.6^{*}$ & 10.1 & D15 & $11^{*}$ \\
\hline
\end{tabular}

${ }^{*}$ Different from ecotype Bagual within the same column at $p \leq 0.05$. 
parents, until the fourth cutting. However, in the last cut, the male parents surpassed them in terms of TDM. The female parent C44X had low productivity during the entire period of evaluation. On the other hand, Q4188 was the most productive female parent, with higher dry mass production than the average of its progenies. Family $\mathrm{E}$ presented the lowest dry mass production, followed by family $A$, whereas families $B, C, D$, and $F$ had a very similar performance with higher production levels than the remaining two families did.

Regarding growth habit among the 20 most productive plants, eight were erect, while 12 had a prostrate growth habit (Table 2). Erect plants invest less in reserve structures, such as aboveground rhizomes, and this may influence their survival under high grazing intensity or environmental stresses, such as cold stress during winter. Pedreira and Brown (1996) evaluated the growth habit and persistence of Paspalum notatum accessions and observed that plants with greater plant height, but fewer aboveground rhizomes showed less survival rates following winter.

$P$. notatum is most often found in fields with low forage height due to its ability to support excessive grazing, due to the presence of survival structures (Nabinger et al., 2009). The erect types may require management that is more careful. The five least productive hybrids had a prostrate growth habit. Pedreira and Brown (1996) reported that selection for increased productivity in $P$. notatum seems to result in taller plants with fewer reserve structures (rhizomes) and with a greater tendency to suffer cold damage. Leaf coloration due to anthocyanin accumulation was evaluated during winter. High variation in leaf color was observed, with scores ranging from 0 to 10 (Table 2). However, correlations between anthocyanin accumulation and frost effect $(\mathrm{r}=0.03)$ or plant survival following winter $(\mathrm{r}=$ 0.01) were not observed in this study (Table 3).

Table 2 - Number of tillers per plant, plant growth habit, anthocyanin coloration, cold tolerance, and survival following winter of the 20 most productive hybrids, female parents, male parents, cultivar Pensacola, and the five least productive hybrids.

\begin{tabular}{|c|c|c|c|c|c|}
\hline Genotype & $\begin{array}{l}\text { Average number of } \\
\text { Tillers per plant }\end{array}$ & $\begin{array}{c}\text { Plant } \\
\text { growth habit }\end{array}$ & $\begin{array}{l}\text { Anthocyanin } \\
\text { Coloration }^{1}\end{array}$ & $\begin{array}{c}\text { Cold } \\
\text { Tolerance }{ }^{2}\end{array}$ & $\begin{array}{c}\text { Survival } \\
\text { following winter }\end{array}$ \\
\hline D3 & 1144 & Erect & 3 & 2 & 3 \\
\hline D16 & 970 & Prostrate & 2 & 2 & 3 \\
\hline C17 & 855 & Erect & 6 & 2 & 3 \\
\hline $\mathrm{C} 2$ & 860 & Prostrate & 1 & 3 & 3 \\
\hline B17 & 1137 & Prostrate & 5 & 3 & 3 \\
\hline D17 & 957 & Erect & 0 & 2 & 3 \\
\hline B43 & 985 & Prostrate & 7 & 2 & 4 \\
\hline C24 & 922 & Prostrate & 4 & 2 & 4 \\
\hline D25 & 922 & Erect & 5 & 2 & 3 \\
\hline $\mathrm{C} 18$ & 919 & Prostrate & 6 & 3 & 3 \\
\hline F15 & 1011 & Prostrate & 6 & 3 & 2 \\
\hline F29 & 989 & Prostrate & 6 & 3 & 2 \\
\hline B26 & 830 & Prostrate & 4 & 2 & 3 \\
\hline B37 & 909 & Erect & 3 & 2 & 3 \\
\hline F24 & 986 & Prostrate & 5 & 3 & 2 \\
\hline C32 & 901 & Erect & 4 & 3 & 3 \\
\hline C9 & 827 & Prostrate & 5 & 3 & 3 \\
\hline C6 & 911 & Erect & 5 & 2 & 3 \\
\hline C15 & $660^{*}$ & Prostrate & 5 & 2 & 3 \\
\hline B29 & 713 & Erect & 7 & 2 & 4 \\
\hline Bagual & 1053 & Prostrate & 5 & 3 & 2 \\
\hline André da Rocha & 945 & Prostrate & 5 & 3 & 3 \\
\hline Q4188 & $480^{*}$ & Erect & 4 & 2 & 3 \\
\hline Q4205 & $143^{*}$ & Erect & 6 & 2 & 1 \\
\hline C44X & $237^{*}$ & Prostrate & 0 & 3 & 1 \\
\hline 'Pensasola' & $324^{*}$ & Prostrate & 4 & 3 & 1 \\
\hline E5 & $144^{*}$ & Prostrate & 3 & 3 & 1 \\
\hline F5 & $95^{*}$ & Prostrate & 5 & 2 & 1 \\
\hline A35 & $118^{*}$ & Prostrate & 8 & 2 & 2 \\
\hline D21 & $101^{*}$ & Prostrate & 3 & 2 & 1 \\
\hline D15 & $53^{*}$ & Prostrate & 9 & 3 & 1 \\
\hline
\end{tabular}


Costa and Scheffer-Basso (2003) reported that $P$. dilatatum leaves become purplish during winter, indicating high anthocyanin content. The purplish leaf color in winter grasses has been associated with the accumulation of soluble carbohydrates. It has also been associated with plant growth habit and growth under cold temperatures. In Agropyrum sp., leaf anthocyanin coloration was found to be negatively correlated with plant height and positively with the prostrate growth habit, indicating that it may be an effective phenotypic marker for slow growth under low temperatures (Hu et al., 2001). This contrasts with the present study, since a significant correlation between anthocyanin coloration and plant growth habit was not observed. Moon et al. (2006) reported that anthocyanin accumulation occurs in response to stresses, and changes in leaf color were observed even though no frost occurred before evaluation.

Regarding the visual evaluation of cold effects on plants following winter, all plants presented winterkilled leaves, with damage varying from moderate to severe. A high correlation was observed between frost effect and plant growth habit $(\mathrm{r}=0.97)$. The most productive hybrids were those with higher survival and regrowth following the winter. Regrowth was significantly correlated with total dry mass production for the first cutting in the spring $(\mathrm{r}=0.60)$.

The Pearson product-moment correlation coefficients between leaf dry mass (LDM), stem dry mass (SDM), inflorescence dry mass (IDM), total dry mass (TDM), number of tillers, and plant height are presented in Table 4. Leaf dry mass had the highest correlation

Table 3 - Pearson correlation coefficient for total dry mass (TDM), total dry mass for cutting 3 (C3 TDM), number of tillers, plant growth habit, anthocyanin coloration, effect of frost, and survival following winter.

\begin{tabular}{|c|c|c|c|c|c|c|}
\hline Variable & TDM & C3 TDM & Tillers & Habit & Anthocyanins & Frost Surviva \\
\hline \multicolumn{7}{|l|}{ TDM } \\
\hline C3 TDM & $0.63^{*}$ & & & & & \\
\hline Tillers & $0.78^{*}$ & $0.48^{*}$ & & & & \\
\hline Habit & 0.06 & $0.24^{*}$ & 0.02 & & & \\
\hline Anthocyanins & 0.04 & $0.12^{*}$ & 0.04 & 0.03 & & \\
\hline Frost & 0.05 & $0.23^{*}$ & 0.01 & $0.97^{*}$ & 0.03 & \\
\hline Survival & $0.49^{*}$ & $0.60^{*}$ & $0.33^{*}$ & $0.30^{*}$ & 0.01 & $0.30^{*}$ \\
\hline
\end{tabular}

Table 4 - Pearson product-moment correlation coefficients between leaf dry mass (LDM), stem dry mass (SDM), inflorescence dry mass (IDM), total dry mass (TDM), number of tillers and plant height.

\begin{tabular}{lcccccc}
\hline Variable & LDM & SDM & IDM & TDM & Tillers & Height \\
\hline LDM & & & & & & \\
SDM & $0.62^{*}$ & & & & & \\
IDM & $0.56^{*}$ & $0.89^{*}$ & & & & \\
TDM & $0.93^{*}$ & $0.86^{*}$ & $0.80^{*}$ & & & \\
Tillers & $0.72^{*}$ & $0.67^{*}$ & $0.67^{*}$ & $0.78^{*}$ & & \\
Height & $0.16^{*}$ & $0.15^{*}$ & $0.06^{*}$ & $0.16^{*}$ & 0.01 & \\
${ }^{*} p \leq 0.05$. & & & & & &
\end{tabular}

with total dry mass, with $\mathrm{r}=0.93 \%$. This indicates that it would not be necessary to separate plants into leaves, stems, and inflorescences prior to analysis to maintain the efficiency of selection of the best genotypes. Further investigation is required, since significant time savings could be achieved by eliminating this process.

Total dry matter was obtained by adding LDM, SDM and IDM. These variables were therefore expected to be highly correlated with TDM, as observed (Table 4). The only non-significant correlation observed was between plant height and the number of tillers. Even when plant height was observed to be correlated with other variables, these correlations had little biological significance, with only $16 \%$ of their effect being explained by the correlated variable. The low correlation between plant height and TDM may have been due to the growth habit of some hybrids. Hybrids with a prostrate growth habit invest more in reserve structures, growing closer to the ground, therefore present lower plant height and do not always show high TDM productivity.

The partial diallel analysis involves the evaluation of two parental groups, either belonging to or not belonging to a common set, with inferences performed for each group separately (Cruz et al., 2004). The parents of one group are represented by constant numbers, which can differ from the number of hybrid combinations where the other group of parents is represented. Different methods of the partial diallel analysis use data from different generations, most commonly $\mathrm{F}_{1}$ or parents and their $\mathrm{F}_{1}$ progeny. These methods supply different genetic information, namely the general and specific combination capacity or the parental potential per se and heterotic effects, using genetic parameters adapted from Griffing (1956). The partial diallel, crossing scheme for TDM production of the hybrid combinations of two male and three female parents is presented in Table 5. The values are averages of four replicates of each hybrid, e.g. for the crossing between André da Rocha and Q4188, 28 hybrids and respective replicates were considered, and 146.2 is the average TDM production for all progeny.

The GCA is used to designate the average performance of a parental line for all crossings in which it participates (Sprague and Tatum, 1942) and is associated with allele and epistatic additive effects. The general

Table 5 - Average total dry mass (TDM) yield for hybrids resulting from the crossing between male parents Bagual and André da Rocha (AR) and female parents Q4188, Q4205, and C44X.

\begin{tabular}{lccc}
\hline \multirow{2}{*}{ Female parents } & \multicolumn{2}{c}{ Male parents } & \multirow{2}{*}{ Total } \\
\cline { 2 - 3 } & AR & Bagual & \\
\hline Q4188 & 146.2 & $205.3^{*}$ & 351 \\
Q4205 & $227.2^{*}$ & $231.8^{*}$ & 459 \\
C44X & 75.8 & 182.9 & 258 \\
Total & 449.2 & 620.0 & 1069 \\
\hline${ }^{*} p \leq 0.05$. & & &
\end{tabular}


combining ability explains the proportion of genotypic variance due to the additive effects of genes (Trindade et al., 2015). High GCA, either positive or negative, indicates parental lines that are greatly superior or inferior to the other lines in the diallel crossing. GCA values close to zero indicate performance that does not differ from the overall average for all hybrid combinations (Cruz et al., 2004).

On the other hand, SCA is used to designate cases in which certain hybrid combinations are relatively different from what would be expected based on the average performance of the two parental lines (Sprague and Tatum, 1942). Falconer (1981), however, defined SCA as the deviation of the average performance for a given combination from the average of the respective parental lines. The specific combining ability indicates the importance of non-additive interactions resulting from gene complementation between parental lines, allowing the prediction of genetic gains due to heterosis (Borges et al., 2011).

The highest GCA values were observed for male parent Bagual and female parent Q4205 (Table 6). These two parents are therefore recommended for the formation of base populations for future selections. The genotype Q4205 invested little in reserve structures and presented erect growth habit. A large part of its dry mass could be removed by cutting or grazing. By contrast, female parent $\mathrm{C} 44 \mathrm{X}$ invested a large part of its photoassimilates in reserve structures, presenting a prostrate growth habit and shorter leaves.

In contrast, when there is interest in using a specific parent to create hybrids, SCA estimates are useful to select the best parental combination (Silva et al., 2013). If, for example, there is a particular interest in Q4205, a cross with Bagual is recommended, since the resulting hybrids showed the highest SCA.

A further study is being conducted to evaluate the most productive hybrids in larger plots by observing their agronomic behavior and evaluating their productivity in a homogeneous environment with competition for light and nutrients. The mode of reproduction (apomictic or sexual) of the selected hybrids was evaluated using cytoembryological analysis and molecular markers (Weiler et al., 2017). Once the agronomical value of the apomictic genotypes is confirmed, they will be registered and protected as cultivars, and sexual plants with high productivity may remain in the program to be used as a female parent in future crossings.

Table 6 - Estimates of General Combining Ability and Specific Combining Ability effects between male parents Bagual and André da Rocha (AR) and female parents Q4188, Q4205 and C44X.

\begin{tabular}{|c|c|c|c|c|}
\hline \multicolumn{2}{|c|}{ General Combining Ability } & \multicolumn{3}{|c|}{ Specific Combining Ability } \\
\hline Female Parent & Male Parent & Female Parent & Mal & rent \\
\hline & & & AR & Bagual \\
\hline Q4188 & -28.5 & Q4188 & -1.1 & 1.1 \\
\hline Q4205 51.3 & Bagual 28.5 & Q4205 & 26.2 & -26.2 \\
\hline $\begin{array}{ll}C 44 X & -48.9 \\
\end{array}$ & & C44X & -25.1 & 25.1 \\
\hline
\end{tabular}

\section{Conclusions}

Evaluation of dry mass production of the hybrids showed genotypes with high hybrid vigor and higher productivity than most productive parents did. In addition, the most productive hybrids showed the most vigorous regrowth following winter and are candidate to be assessed on yield trials to become a commercial variety.

In this study, there is no correlation between anthocyanin coloration and effect of cold tolerance or regrowth following winter and no correlation between plant growth habit and dry mass production. There is, however, a strong positive correlation between plant growth habit and effect of frost damage.

The best parents to be used in future crossings are ecotype Bagual (male) and genotype Q4205 (female), since their progenies presented superior characteristics and a high potential to form superior hybrids. These new hybrids have a great potential to become new cultivars for farmers, contributing not only to animal production, but also to the seed industry.

Leaf dry mass was highly correlated with total dry mass, indicating that, in future studies, it may not be necessary to separate the plant parts in order to effectively evaluate forage yield. This option will save time, money and will contribute to accelerate the selection process, since less labor will be needed.

\section{Acknowledgements}

We acknowledge the Brazilian National Council for Scientific and Technological Development (CNPq, Brazil, Edital Universal 2010, proc. 471318/2010-8) and South-Brazilian Association for the Promotion of Forage (Sulpasto) for financial support and grants.

\section{References}

Borges, V.; Sobrinho, F.S.; Ledo, F.J.S.; Kopp, M.M. 2011. Association between traits and path analysis in half-sib progeny selection of Brachiaria ruziziensis. Revista Ceres 58: 765-772 (in Portuguese, with abstract in English).

Burton, G.W. 1948. Artificial fog chamber facilitates Paspalum emasculation. Journal American Society of Agronomy 40: 281282.

Cidade, F.W.; Vigna, B.B.Z.; Souza, F.H.D.; Valls, J.F.M.; Dall'Agnol, M.; Zucchi, M.I.; Souza-Chies, T.T.; Souza, A.P. 2013. Genetic variation in polyploid forage grass: assessing the molecular genetic variability in the Paspalum genus. BMC Genetics 14: 1-18.

Costa, D.I.; Scheffer-Basso, S.M. 2003. Morphophysiological and agronomic characterization of Paspalum dilatatum Poir. biotype Virasoro and Festuca arundinacea Schreb. 1. Morphological development. Revista Brasileira de Zootecnia 32: 1054-1060 (in Portuguese, with abstract in English).

Cruz, C.D.; Regazzi, A.J.; Carneiro, P.C.S. 2004. Biometric Models Applied to Genetic Improvement $=$ Modelos Biométricos Aplicados ao Melhoramento Genético. Editora da Universidade Federal de Viçosa, Viçosa, MG, Brazil (in Portuguese). 
Falconer, D.S. 1981. Introduction to quantitative genetics. Longman, New York, NY, USA.

Forbes, I.; Burton, G.W. 1961. Induction of tetraploid and rapid field method of detecting induced tetraploidy in Pensacola bahiagrass. Crop Science 1: 383-384.

Griffing, B. 1956. Concept of a general and specific combination ability in relation to diallel crossing systems. Australian Journal of Biological Sciences 9: 463-493.

Hu, Z.; Wang, R.R.C.; Larson, S.R. 2001. Selection response for molecular markers associate with anthocyanin coloration and low-temperature growth traits in crested wheatgrass. Canadian Journal of Plant Science 81: 665-671.

Moon, Y.J.; Wang, X.; Morris, M.E. 2006. Dietary flavonoids: effects on xenobiotic and carcinogen metabolism. Toxicology in Vitro 20: 187-210.

Nabinger, C.; Ferreira, E.T.; Freitas, A.K.; Carvalho, P.C.F.; Sant'Anna, D.M. 2009. Animal production based on the native pastures: applications of research results. = Produção animal com base no campo nativo: aplicações de resultados de pesquisa. p. 175-198. In: Pillar, V.P.; Müller, S.C.; Castilhos, Z.M.S.; Jacques, A.V.A., eds. Southern pastures: conservation and sustainable use of biodiversity $=$ Campos sulinos: conservação e uso sustentável da biodiversidade. Ministério do Meio Ambiente, Brasília, DF, Brazil (in Portuguese).

Ortiz, J.P.A.; Quarín, C.L.; Pessino, S.C.; Acuña, C.; Martínez, E.J.; Espinoza, F.; Hojsgaard, D.H.; Sartor, M.E.; Cáceres, M.E.; Pupilli, F. 2013. Harnessing apomictic reproduction in grasses what we have leamed from Paspalum. Annals of Botany 112: 767-787.

Pedreira, C.G.S.; Brown, R.H. 1996. Physiology, morphology, and growth of individual plants of selected and unselected bahiagrass populations. Crop Science 36: 138-142.

Quarín, C.L.; Espinoza, F.; Martínez, E.J.; Pessino, S.C.; Bovo, O.A. 2001. A rise of ploidy level induces the expression of apomixis in Paspalum notatum. Sexual Plant Reproduction 13: 243-249.
Quarín, C.L.; Urbani, N.H.; Blount, A.R.; Martínez, E.J.; Hack, C.M.; Burton, G.W.; Quesenberry, K.H. 2003. Registration of Q4188 and Q4205, sexual tetraploid germplasm lines of bahiagrass. Crop Science 43: 745-746.

Rebozzio, R.N.; Rodríguez, M.P.; Stein, J.; Ortiz, J.P.A.; Quarín, C.L.; Espinoza, F. 2012. Validation of molecular markers linked to apospory in tetraploid races of bahiagrass, Paspalum notatum Flüggé. Molecular Breeding 29: 189-198.

Silva, V.M.P.; Carneiro, P.C.S.; Menezes Júnior, J.A.N.; Carneiro, V.Q.; Carneiro, J.E.S.; Cruz, C.D.; Borém, A. 2013. Genetic potential of common bean parents for plant architecture improvement. Scientia Agricola 70: 167-175.

Simioni, C.; Valle, C.B. 2011. Meiotic analysis in induced tetraploids of Brachiaria decumbens Stapf. Crop Breeding and Applied Biotechnology 11: 43-49.

Sprague, G.F; Tatum, L.A. 1942. General vs specific combining ability in single crosses of corn. Journal American Society of Agronomy 34: 923-932.

Trindade, R.S.; Rodrigues, R.; Amaral Júnior, A.T.; Gonçalves, L.S.A.; Viana, J.M.S.; Sudré, C.P. 2015. Combining ability for common bacterial blight resistance in snap and dry bean (Phaseolus vulgaris L.). Acta Scientiarum. Agronomy 37: 37-43.

Weiler, R.L.; Krycki, K.C.; Guerra, D.; Simioni, C.; Dall'Agnol, M. 2015. Chromosome doubling in Paspalum notatum var. saure (cultivar Pensacola). Crop Breeding and Applied Biotechnology 15: 106-111.

Weiler, R.L.; Dall'Agnol, M.; Simioni, C.; Krycki, K.C.; Dahmer, N.; Guerra, D. 2017. Determination of the mode of reproduction of bahiagrass hybrids using cytoembryological analysis and molecular markers. Revista Brasileira de Zootecnia 46 (3): 185-191. 